\title{
The Relationship Between Longevity and a Leader's Emotional Intelligence and Resilience
}

\author{
Erica L. Allen ${ }^{1}$ \\ ${ }^{1}$ Department of Educational Leadership, University of Montana, Missoula, Montana, USA \\ Correspondence: Erica Allen, Educational Leadership Department, Missoula, MT, USA.
}

Received: October 15, 2021

Accepted: November 19, 2021

Online Published: November 23, 2021

doi:10.5539/jel.v11n1p101

URL: https://doi.org/10.5539/jel.v11n1p101

\begin{abstract}
The role of an educational leader is complex, challenging and, at times, fraught with adversity. Overcoming the many challenges and hardships, and flourishing as an educational leader, requires resilience and an instinct for survival. According to Maulding, Leonard, Peters, Roberts and Sparkman (2012), understanding how to prevail in the face of difficult conditions, by employing one's emotional strengths as well as vulnerabilities and how to increase one's ability to remain resilient, is valuable for an educational leader to succeed in the face of adversity. The purpose of this study was to research Montana educational leaders to discern whether emotional intelligence (EI) is necessary to remain resilient and successful in a leadership role despite adversity. This quantitative research was undertaken as a non-experimental, ex post facto, or after-the-fact research. Participants for this study included sixty-one superintendents, principals, and assistant principals, from a population of 935 educational leaders, who held a leadership position in the State of Montana during the 2017-2018 school year. A linear regression was used to examine the proportion of variance in years in a leadership position that can be explained by emotional intelligence and resilience. This analysis demonstrated that some EI competencies appear to have an effect on the longevity of an educational leader in a position. However, the effects vary between assistant principals, principals, and superintendents, not all competencies were equal. The coefficient of determination showed assistant principals and principals' years of service is more strongly influenced by all emotional intelligence competencies than is that of the superintendent.
\end{abstract}

Keywords: ability, adversity, competency, educational leader, emotional intelligence, longevity, resilience

\section{Introduction}

Emotional Intelligence is defined as an, “...emotional-social intelligence which includes one or more of the following key components: (a) the ability to recognize, understand and express emotions and feelings; (b) the ability to understand how others feel and relate with them; (c) the ability to manage and control emotions; (d) the ability to manage change, adapt and solve problems of a personal and interpersonal nature; and (e) the ability to generate positive affect and be self-motivated" (Bar-On, 2006, p. 1). The role of an educational leader is complex, challenging and, at times, fraught with adversity (Patterson \& Patterson, 2004). Increasingly, "those in leadership roles have a tremendous responsibility to get it right" (Leithwood, Harris, \& Hopkins, 2008, p. 1). In recent years the job of an educational leader has been "expanded and, perhaps, overloaded" (Manna, 2015, p. 6), making the job ever more difficult. Doyle and Locke (2014) admonished, "at a time when schools need high-quality leaders more than ever, the grueling nature of the job makes it a tough sell" (p. 7). In a quickly changing and often volatile educational environment, leaders are required to make difficult, sometimes unpopular, decisions. Maulding, Leonard, Peters, Roberts, and Sparkman (2012) asserted that understanding how to prevail in the face of adversity, by employing one's emotional strengths as well as vulnerabilities and how to increase one's ability to remain resilient, is essential for an educational leader to succeed in the face of adversity. According to Ackerman and Maslin-Ostrowski (2004), the "...landscape of education leadership in the 21 st century offers an astounding range of emotional challenges rarely acknowledged or appreciated" (para. 2). The questioning of a leader's decisions, motives or integrity can cause deep wounds on a very personal level. When this happens, the hurt feels personal, thus being challenging to overcome (Martin, 2007; Ackerman \& Maslin-Ostrowski, 2004). "For many educators, a kind of weariness or wariness has set in as expectations for performance-their own as well as their students'-sometimes far exceed well-intentioned effort. This dissonance in the education profession makes leadership a risky business" (Ackerman \& Maslin-Ostrowski, 2004, para. 11). As a result of this risk, many leaders 
choose to leave the profession all together after extreme hardship, thus diminishing an already sparse leadership pool. According to Mendels (2016), "School district officials have faced an urgent task in recent years: ensuring that all schools, not just a lucky few, benefit from surefooted leadership professionals" (p. 6). Because their role bears the hopes, aspirations and fears of those they serve, it is one of vulnerability. When adversity and wounding are inevitable, leaders are going to find it difficult to live up to the superhero status too often expected of them and many will leave the profession (Ackerman \& Maslin-Ostrowski, 2004; Klitz, Danzig, \& Szecsy, 2004). Burns-Neilson (2002) completed a study for the Montana Office of Public Instruction entitled Who Will Teach Montana's Children. This research ranked superintendents and principals as being among the most difficult positions to fill in Montana schools. In today's world, education is changing quickly and expectations for success are high. This study was meant to research Montana educational leaders to determine whether a high level of Emotional Intelligence (EI) is needed in order for leaders to persevere in their positions with a genuine sense of self, grounded in their individual strengths and vulnerabilities, and remain effective, strong leaders.

\subsection{Purpose Statement}

The purpose of this study was to research Montana educational leaders to discern whether emotional intelligence (EI) is necessary to remain resilient and successful in a leadership role despite adversity. By studying these leaders this research hoped to determine whether a high level of EI would empower leaders to remain resilient and persistently overcome adversity. This information would provide leaders with insight that can enable them to better realize their own continued achievement and lead their schools to success.

\subsection{Research Questions and Hypothesis(es)}

According to Maulding, Leonard, Peters, Roberts, and Sparkman (2012), understanding EI and its relationship to overcoming adversity is valuable in building resiliency in leadership. This resiliency is expedient to effectively fulfilling a long-term leadership role. To best understand emotional intelligence and how it is used, continued research is necessary. Therefore, the question that guided this research was: What is the relationship between longevity in an educational leadership position and a leader's emotional intelligence and resilience in the face of adversity? The research hypothesis is as follows: There is a relationship between an educational leader's longevity in a position and their emotional intelligence and resilience in the face of adversity.

\section{Method}

This quantitative research was undertaken as a non-experimental, ex post facto or after-the-fact research, “...in which the investigation starts after the fact has occurred without interference from the researcher" (Salkind, 2010, p. 466). The Emotional and Social Competence Inventory (ESCI), using Boyatzis' (2009) work on the theoretical organization of personality, linked to a theory of action and job performance, was employed to determine each leader's EI. The Adversity Response Profile (ARP) instrument (Stoltz, 2001) (Appendix A), developed to determine adversity response, was utilized to gauge the leader's ability to overcome adversity. The number of years an educational leader had worked in their current position determined their longevity. These years were self-reported.

\subsection{Data Collection Procedures}

The data representing EI and resilience consisted of original source data, obtained through the administration of the ESCI to individual participants. The Korn Ferry group owns and manages the ESCI instrument. To gather emotional intelligence data using the ESCI inventory, the researcher emailed a survey link to each participant along with directions for taking the survey. When all surveys were complete, a representative from the Korn Ferry group sent the researcher the compiled data. The statistical analysis was then completed on this data using the $I B M$ SPSS Statistic analysis program. According to Stolz (2010), the ARP instrument was developed to test how people unconsciously respond to adversity, which is an indicator of an individual's resilience. Because of this, data from the ARP instrument was utilized to gauge the leader's ability to overcome adversity and remain resilient. The instrument used a Likert scale with 5 response points, completed by the individual participants. To gather resilience data, the researcher developed a survey using the ARP instrument and the Qualtrics survey platform. The Qualtrics survey link was sent to each participant for them to complete the survey. After all surveys were completed, the researcher compiled data using the Qualtrics platform and performed statistical analysis on the data, using the SPSS predictive analysis program. Years of longevity in a leader's current position, as provided by participants, was used to test the dependent variable. Participants reported their years of longevity through the ESCI instrument.

\subsection{Data Analysis}

The research question posed in the study was answered through the analysis of sets of data on EI and resilience and 
leadership longevity. The researcher used a simple linear regression analysis, where the "...predictors are not only correlated with the criterion, but they also are correlated with the other predictors" (Steinberg, 2011, p. 491). Pallant (2010) stated, "multiple regression is based on correlation, but allows a more sophisticated exploration of the interrelationship among a set of variables" (p. 148). IBM SPSS Statistics was used to run the research data for simple linear regression analyses. Data from both the ESCI and the ARP instruments were obtained using a Likert scale. A Pearson's $r$ correlation coefficient was used to "... measure the strength of the relationship between two variables" (Hauke \& Kossowski, 2011, p. 88).

\section{Results}

Linear regression was used to examine the proportion of variance in the dependent variable that could be explained by emotional intelligence and resilience. Experimental importance was defined as $.500 \mathrm{R}^{2}$ value, which tells us that $50 \%$ of the variance in a leader's longevity can be explained by the independent variable. Alpha was set at .05 . Linear regression analyses determined the effect size of the observation. As was stated by Cohen (1994), "...a correlation greater than .30 is medium and one of .40 is large" (as cited in Steinberg, 2011, p. 493).

To evaluate the reliability of the scales, Cronbach's alpha test was used to measure internal consistency. According to Tavakol and Dennick (2011), "...internal consistency describes the extent to which all the items in a test measure the same concept or construct and hence it is connected to the inter-relatedness of the items within the test" (p. 1). This measurement is expressed as a number between 0 and 1 . Chronbach (1970) stated that scores of .70 or higher indicate an acceptable level of reliability. Analysis from the Korn Ferry group (2011), the administrators of the ESCI instrument, stated the following competencies received individual scores; this further indicates an acceptable level of validity, as is shown in Table 1 .

Table 1. Chronbachs Alpha scores

\begin{tabular}{ll}
\hline Competency & $a$ \\
\hline Positive Outlook & .86 \\
Organizational Awareness & .86 \\
Inspirational Leadership & .89 \\
Influence & .84 \\
Empathy & .86 \\
Emotional Self-Control & .91 \\
Emotional Self-Awareness & .83 \\
Conflict Management & .79 \\
Coach and Mentor & .92 \\
Adaptability & .85 \\
Achievement Orientation & .86 \\
Adversity Response & .81 \\
\hline
\end{tabular}

Table 2 shows the standard error of estimate calculations, which according to Holcomb (2017), determines the amount of dispersion for the prediction equation. The standard error of the estimate was assessed to establish the variability and dispersion of each regression model. As a precautionary note, according to Norušis (2005), with the small samples of $\mathrm{n}=11,21$, and 24 , the standard error of the estimate might have been inordinately small.

The standard error of the estimate calculations portray the largest variability, or dispersion, for assistant principal population to be included in inspirational leadership competency. The least variability in the assistant principal population is shown for the coach and mentor competencies. Analysis for the population of principals shows a larger dispersion and lesser uniformity than the assistant principal and superintendents' data analysis. The adaptability competency, which shows more uniformity, is the exception; thus, it is closer to the population mean. Analysis for the superintendent population shows calculations for all competencies to have low variabilities, except for the dispersion of conflict management competency. 
Table 2. Standard error of the estimate

\begin{tabular}{llllll}
\hline Competency & Assistant Principal & Principal & Superintendent & Total & Mean \\
\hline Positive Outlook & 0.83 & 1.13 & 0.86 & 2.82 & 0.94 \\
Organizational Awareness & 0.87 & 1.13 & 0.87 & 2.88 & 0.96 \\
Inspirational Leadership & 2.27 & 1.12 & 0.87 & 4.26 & 1.41 \\
Influence & 0.87 & 1.12 & 0.86 & 2.86 & 0.95 \\
Empathy & 0.77 & 1.13 & 0.87 & 2.78 & 0.93 \\
Emotional Self-Control & 0.80 & 1.14 & 0.81 & 2.75 & 0.92 \\
Emotional Self-Awareness & 0.79 & 1.11 & 0.88 & 2.79 & 0.93 \\
Conflict Management & 0.76 & 1.22 & 1.06 & 3.05 & 1.02 \\
Coach and Mentor & 0.68 & 1.13 & 0.87 & 2.68 & 0.89 \\
Adaptability & 0.87 & 0.32 & 0.87 & 2.06 & 0.69 \\
Achievement Orientation & 0.84 & 1.12 & 0.88 & 2.83 & 0.95 \\
\hline
\end{tabular}

In Table 3, the simple linear regression calculations show the prediction of years in an educational leadership position based on the leader's emotional intelligence traits. According to Cohen (1994), statistical hypothesis inference testing shows "... the degree to which the phenomenon is present in the population" (p. 9). For this study, experimental consistency was set at alpha .05 a priori. Accordingly, the ability to coach and mentor was shown to have a statistically significant relationship to the number of years in an assistant principal's position. There were no statistically significance relationships identified between the years in a principal position and any of the related competencies. There was a statistically significant relationship between positive outlook and self-control for the number of years in a superintendent's position. There were no statistically significant relationships between the other eight competencies and longevity in an educational leadership position. These remaining eight competencies failed to reach the a priori threshold of $p<.05$; therefore, this research failed to reject the null hypothesis for these competencies.

Table 3. Regression table

\begin{tabular}{llll}
\hline Competency & Assistant Principal & Principal & Superintendent \\
\hline Positive Outlook & $(F(1,8)=.95, p=.36)$ & $(F(1,21)=1.11, p=.30$ & $(F(1,24)=.05, p=.04)^{*}$ \\
Organizational Awareness & $(F(1,8)=.03, p=.87)$ & $(F(1,21)=.32, p=.58)$ & $(F(1,24)=.15, p=.70)$ \\
Inspirational Leadership & $(F(1,8)=.39, p=.42)$ & $(F(1,21)=.76, p=.40)$ & $(F(1,24)=.68, p=.42)$ \\
Influence & $(F(1,8)=.06, p=.82)$ & $(F(1,21)=.65, p=.43)$ & $(F(1,24)=.68, p=.42)$ \\
Empathy & $(F(1,8)=2.35, p=.16)$ & $(F(1,21)=.12, p=.73)$ & $(F(1,24)=.16, p=.97)$ \\
Self-Control & $(F(1,8)=1.45, p=.26)$ & $(F(1,21)=.00, p=.10)$ & $(F(1,24)=.44, p=.05)^{*}$ \\
Self-Awareness & $(F(1,8)=1.70, p=.23)$ & $(F(1,21)=1.20, p=.29)$ & $(F(1,24)=.04, p=.84)$ \\
Conflict Management & $(F(1,8)=2.50, p=.15)$ & $(F(1,21)=.68, p=.42)$ & $(F(1,22)=.22, p=.15)$ \\
Coach and Mentor & $(F(1,8)=.04, p=.05)^{*}$ & $(F(1,21)=.39, p=.54)$ & $(F(1,24)=.22, p=.65)$ \\
Adaptability & $(F(1,8)=.15, p=.71)$ & $(F(1,21)=.1 .93, p=.18)$ & $(F(1,24)=.17, p=.68)$ \\
Achievement Orientation & $(F(1,8)=.57, p=.47)$ & $(F(1,21)=.76, p=.39)$ & $(F(1,24)=.09, p=.76)$ \\
\hline
\end{tabular}

Note. ${ }^{*} \mathrm{p}<.05$.

While examining the scatterplots within and across variables, the following linear relationships were found. Outliers were present in each of these relationships.

- Assistant principals — organizational awareness, inspirational leadership, influence, empathy, and coach and mentor.

- Principal—self-awareness, adaptability, and conflict management.

- Superintendent-influence, emotional control, conflict management, achievement orientation, self-awareness, and coach and mentor.

Furthermore, coaching and mentoring, positive outlook, and emotional self-control were shown to have a statistically significant relationship for assistant principals and superintendents. 


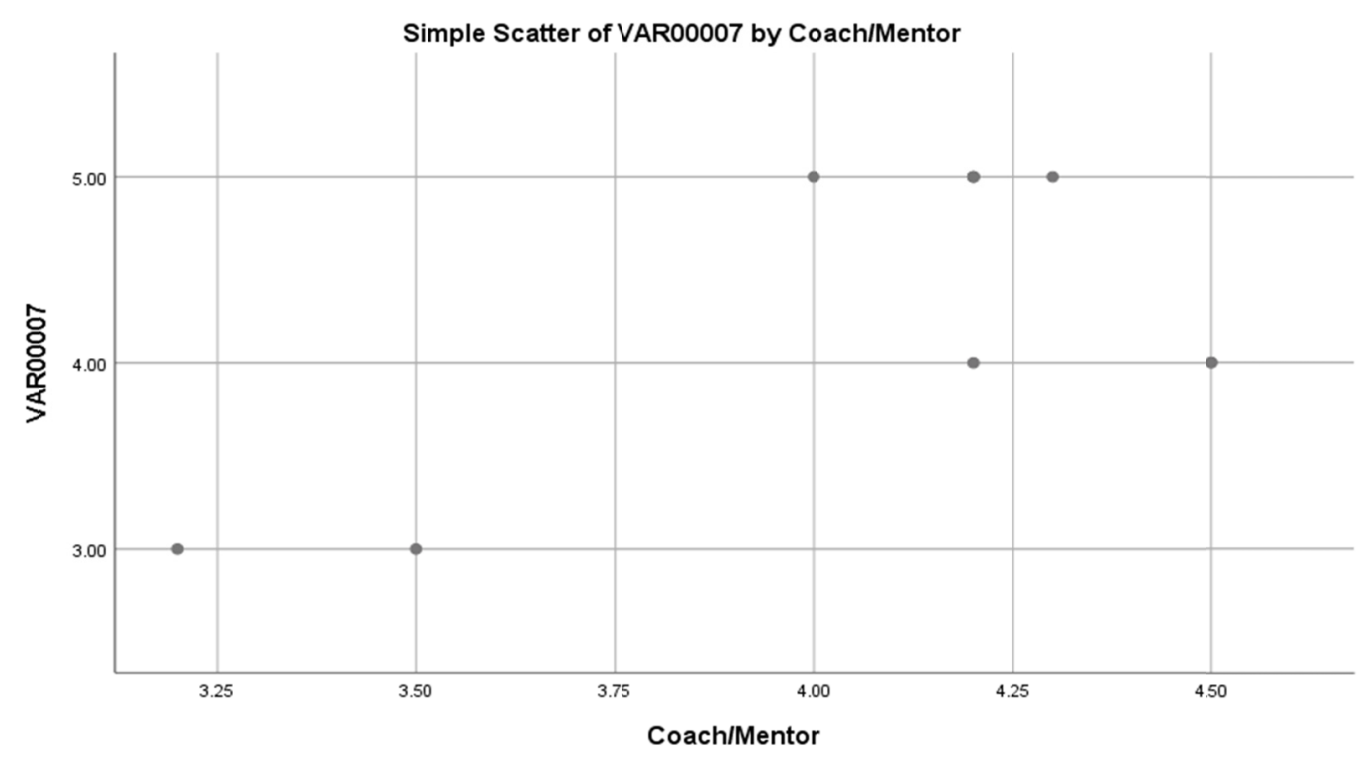

Figure 1. Coach/mentor scatter plot

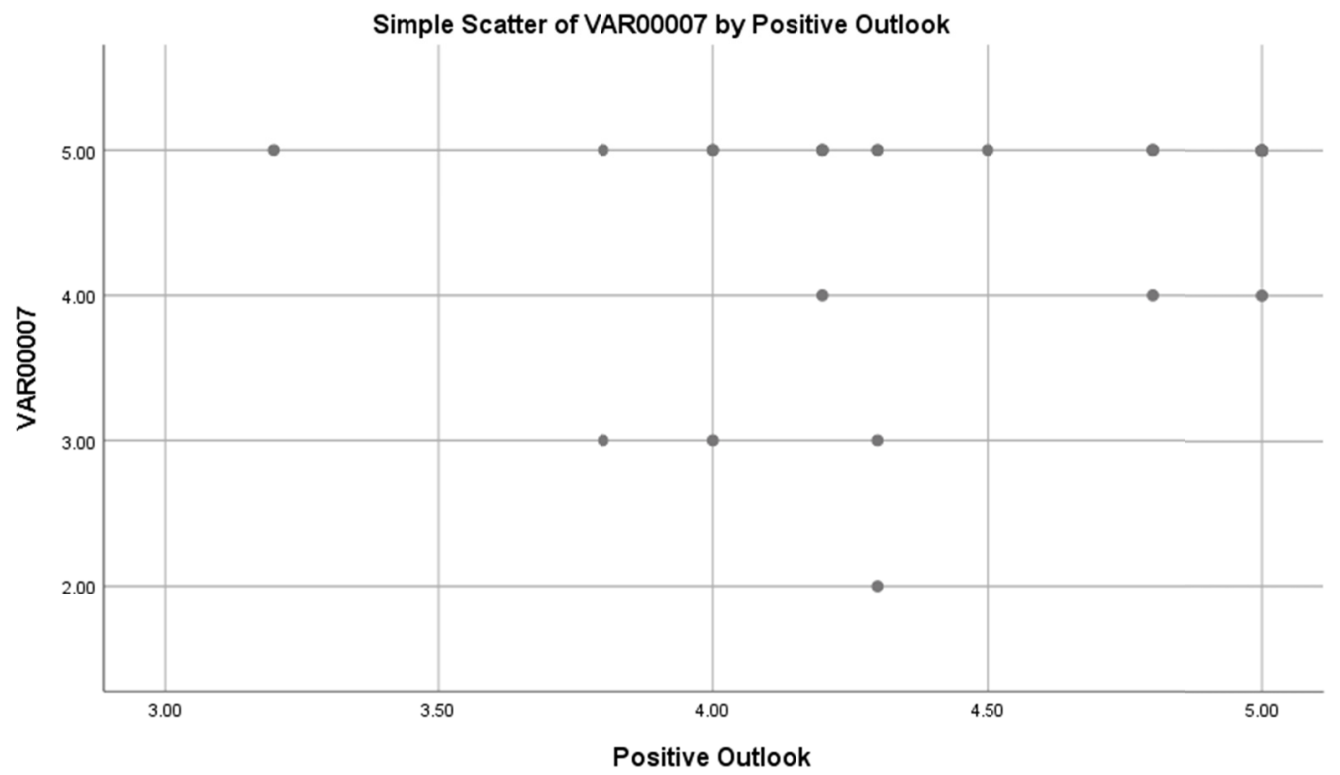

Figure 2. Positive outlook scatter plot 


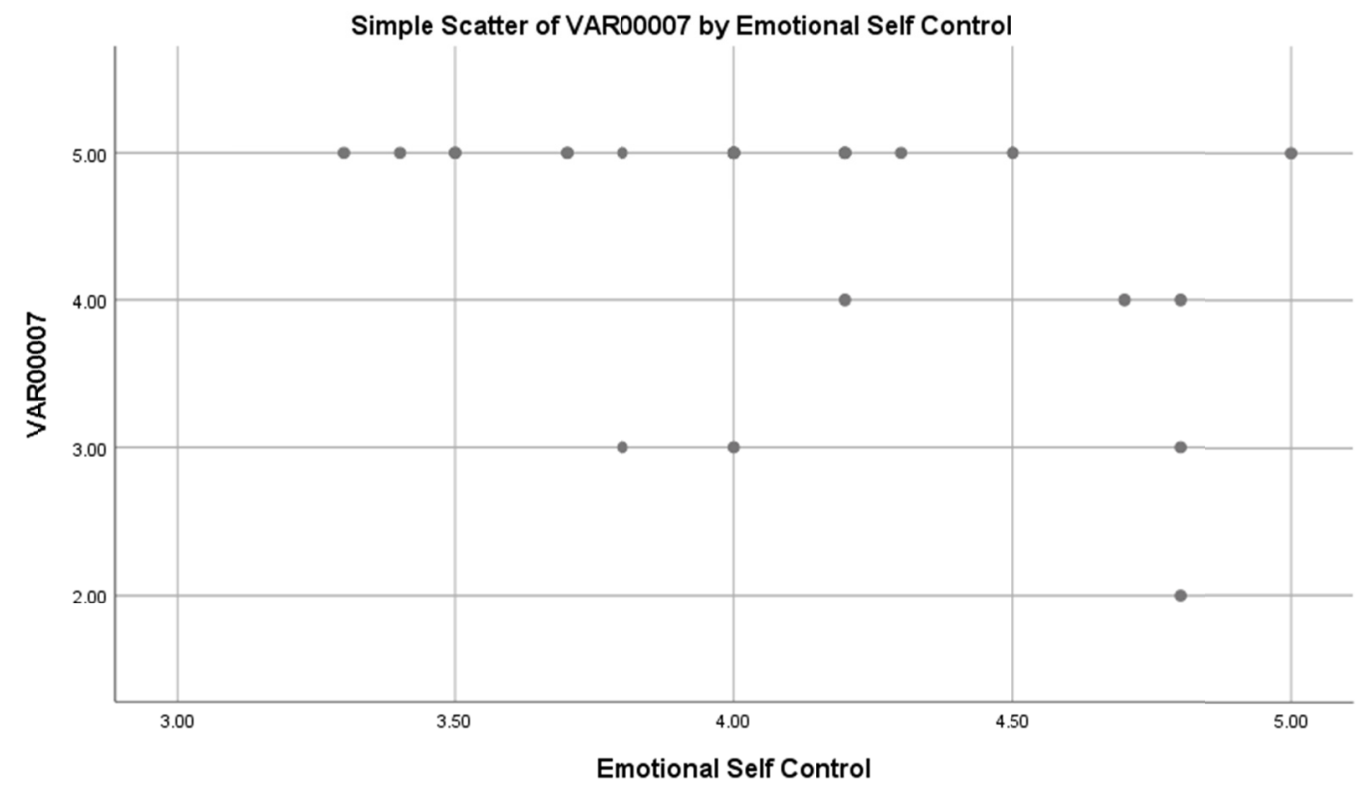

Figure 3. Emotional contral scatter plot

In Table 4, regression calculations show the variance in years of an educational leader's longevity, explained by their emotional intelligence competencies. "R Square, known as the coefficient of determination, indicates the proportion of variance of the dependent variable (years in a leadership position) that can be explained by variation that also occurs in the independent variable" (Holcomb, 2017, p. 117). Accordingly, with a .43 predicted variance, an educational leader's years of service is most greatly influenced by their ability to coach and mentor their staff. With such ability explaining $40 \%$ of the predicted variability in their years of service, this strand of EI is especially important for assistant principals. The ability to adapt to a given situation is a principal's most important EI with an $8.4 \%$ predicted variance, followed by emotional self-awareness, with a $5.4 \%$ variance. According to this data, superintendents benefit the most from the ability to manage conflict, with a $9.1 \%$ variance, and maintain a positive outlook, with a $4.4 \%$ variance.

In Table 4, regression calculations show the variance in years of an educational leader's longevity, explained by their emotional intelligence competencies. "R Square, known as the coefficient of determination, indicates the proportion of variance of the dependent variable (years in a leadership position) that can be explained by variation that also occurs in the independent variable" (Holcomb, 2017, p. 117). Accordingly, with a .43 predicted variance, an educational leader's years of service is most greatly influenced by their ability to coach and mentor their staff. With such ability explaining $40 \%$ of the predicted variability in their years of service, this strand of EI is especially important for assistant principals. The ability to adapt to a given situation is a principal's most important EI with an $8.4 \%$ predicted variance, followed by emotional self-awareness, with a $5.4 \%$ variance. According to this data, superintendents benefit the most from the ability to manage conflict, with a $9.1 \%$ variance, and maintain a positive outlook, with a $4.4 \%$ variance.

Table 4. R Square value

\begin{tabular}{llllll}
\hline Competency & Assistant Principal & Principal & Superintendent & Total & Mean \\
\hline Positive Outlook & 0.11 & 0.02 & 0.04 & 0.17 & 0.05 \\
Organizational Awareness & 0.00 & 0.02 & 0.01 & 0.02 & 0.01 \\
Inspirational Leadership & 0.05 & 0.04 & 0.03 & 0.11 & 0.04 \\
Influence & 0.01 & 0.03 & 0.04 & 0.07 & 0.02 \\
Empathy & 0.23 & 0.01 & 0.01 & 0.24 & 0.08 \\
Emotional Self-Control & 0.15 & 0.00 & 0.01 & 0.16 & 0.05 \\
Emotional Self-Awareness & 0.18 & 0.05 & 0.00 & 0.23 & 0.08 \\
Conflict Management & 0.24 & 0.03 & 0.09 & 0.36 & 0.12 \\
Coach and Mentor & 0.40 & 0.02 & 0.01 & 0.43 & 0.14 \\
Adaptability & 0.02 & 0.08 & 0.01 & 0.11 & 0.04 \\
Achievement Orientation & 0.07 & 0.04 & 0.00 & 0.11 & 0.04 \\
\hline
\end{tabular}


Overall, assistant principals' and principals' years of service is more strongly influenced by all EI competencies than that of the superintendents. This may be so since assistant principals and principals often work more closely with staff and students than superintendents do.

Table 5 shows the effect size calculations from the unstandardized coefficients in the simple linear regression. These calculations were carried out in SPSS, using a linear regression. The unstandardized coefficients predict years in a leadership position, based on the leader's emotional intelligence competencies. The participants' predicted years in a leadership position are equal to years in a leadership position + the competency interval.

The assistant principals' years in a leadership position were most greatly affected by coaching and mentoring, conflict management, and empathy, with gains of 1.24, 1.08, and 1.07 years for each competency interval respectively. Principals showed the largest effects from influence, positive outlook, and organizational awareness. However, these effects were much smaller than that of the assistant principals', with gains of only .39, .37, and .32 years respectively. This could be owed to the disparity in sample sizes. The superintendents' greatest effects came from inspirational leadership and influence. These were much less significant than the assistant principals' effects, of only .34, and .29 years. The greatest effects for the mean of the three leadership strata were coach and mentor, positive outlook, and empathy, with $.36, .30$, and .33 variance respectively.

Inspirational leadership showed the least effect on assistant principals with a decrease of -.102 years for each interval measured. Principals were least affected by achievement orientation, with a decrease of -.53 years for each interval measured. Superintendents were least affected by conflict management and emotional self-control with a decrease of -.73 years for each interval of awareness. Emotional self-awareness showed the least affect of the mean, with a decrease of -.58 years for each interval of awareness.

Table 5. Unstandardized Coefficient effect size

\begin{tabular}{llllll}
\hline Competency & Assistant Principal & Principal & Superintendent & Total & Mean \\
\hline Positive Outlook & $2.48+.42$ & $2.89+.37$ & $4.76+-.11$ & $10.13+.90$ & $3.38+.30$ \\
Organizational Awareness & $3.70+.14$ & $2.75+.32$ & $3.81+.16$ & $10.26+.62$ & $3.42+.21$ \\
Inspirational Leadership & $5.19+-1.02$ & $5.87+-.41$ & $3.38+.34$ & $14.44+.62$ & $4.81+.21$ \\
Influence & $3.67+.16$ & $2.63+.39$ & $3.38+.29$ & $9.68+-.27$ & $3.23+-.09$ \\
Empathy & $-.07+1.07$ & $5.07+-.22$ & $5.08+.14$ & $10.08+.99$ & $3.36+.33$ \\
Emotional Self-Control & $1.68+.62$ & $4.20+-.01$ & $7.53+-73$ & $13.41+-.12$ & $4.47+-.04$ \\
Emotional Self-Awareness & $6.65+. .62$ & $5.65+-.39$ & $4.75+. .06$ & $17.05+-1.74$ & $5.68+-.58$ \\
Conflict Management & $-.28+1.08$ & $6.26+-.50$ & $7.24+.73$ & $13.22+-.15$ & $4.41+-.05$ \\
Coach and Mentor & $.77+1.24$ & $5.42+-.30$ & $3.90+.15$ & $10.09+1.09$ & $3.36+.36$ \\
Adaptability & $3.24+.26$ & $3.83+.09$ & $5.19+-.16$ & $12.26+.19$ & $4.09+.06$ \\
Achievement Orientation & $2.34+.47$ & $6.62+-.53$ & $4.03+.11$ & $12.99+.05$ & $4.33+.02$ \\
\hline
\end{tabular}

Table 6 shows the analysis for adversity response. The standard error of the estimate for adversity response shows a wide variability, with superintendents having the least dispersion. The simple linear regression analysis shows that there is no statistically significant relationship between adversity response and years of service in an educational leadership position; it failed to reach the a priori threshold of $p<.05$. Therefore, this research failed to reject the null hypothesis for adversity response. $\mathrm{R}^{2}$ calculations showed that less than $2 \%$ variability in years of service can be explained by an educational leader's adversity response. The principals' years in a leadership position showed the largest effect from adversity response, with a .07 yearly increase.

Table 6. Adversity response

\begin{tabular}{llll}
\hline Analysis & Assistant Principal & Principal & Superintendent \\
\hline Standard Error of the Estimate & 6.04 & 6.91 & 4.21 \\
Regression & $(F(1,11)=.11, \mathrm{p}<.75)$ & $(F(1,25)=.46, \mathrm{p}<.50)$ & $(F(1,25)=.46, p<.50)$ \\
R Square Value & 0.01 & 0.02 & 0.00 \\
\hline
\end{tabular}

\section{Findings}

As a factor impacting the longevity in an educational leadership role, “...emotional intelligence, the softer side of our intelligences, has considerable implications for the field of leadership" (Maulding, 2002, p. 5). As indicated in the data analysis, the ability to coach and mentor is shown to have a statistically significant relationship to 
longevity and resilience for assistant principals. Moreover, there existed some linearity and consequent effect for inspirational leadership, influence, empathy, and coach and mentor; this supports Rode et al. (2007) findings where EI was shown to be "related to effective interactions among individuals because it helps individuals monitor their own and others' behaviors" (Rode et al., 2007, p. 404).

There is no statistical significance between any of the competencies and the principals' years of leadership. This was an unexpected finding, however, some linearity was found to support a small effect from self-awareness, adaptability, and conflict management. This supports the findings from Salovey et al.'s (1999) theory that emotional self-awareness, self-control expression, and self-management buffer the effects of aversive events. Furthermore, Armstrong, Critchley and Galligan (2011) have stated that the life event-distress relationship was weaker for participants with higher levels of emotional self-awareness, emotional expression, emotional self-control, and, especially, emotional self-management.

There was a statistically significant relationship between positive outlook and self-control for superintendents. This finding concurs with the large body of work that found a positive correlation between emotional intelligence and the higher levels of positive affect, and lower levels of negative affect and greater life satisfaction (Austin, Egan, \& Saklofske, 2005; Austin, Brackett, Mayer, Minski, \& Saklofske, 2003; Brackett, Mayer, \& Warner, 2004; Wing, Byrne, \& Schutte, 2006; Gannon \& Ranzijn, 2004; Schutte \& Malouff, 2011; Schutte, Hollander, Malouff, \& Simunek, 2002). Moreover, significant positive associations have been established with EI, empathy, mood regulation, self-monitoring, and interpersonal relationships (Mayer et al., 1999; Petrides \& Furnham, 2002; Schutte et al., 2007).

Analysis from the coefficient of determination showed that an educational leader's length of service is heavily influenced by their ability to coach and mentor their staff. Since such ability explains $40 \%$ of the variability in their years of service, this strand of EI is especially important for assistant principals. This finding could be because an assistant principal typically works closely with, and often spends considerable time mentoring, their staff. An assistant principal's job performance can be highly dependent on those they lead. Additionally, the effect size analysis indicates the importance of coaching and mentoring, added conflict management, and empathy as being important to an educational leader's resilience and longevity in a position. These competencies can work hand-in-hand in a leadership position, which is supported by research showing a strong relationship between EI and better managerial competencies and leadership effectiveness (Gardner \& Stough, 2002; Rosete \& Ciarrochi, 2005; Wong \& Law, 2002). Furthermore, this is in agreement with Cheng (1994), who advised that "a principal's role is to develop, shape and transform their staff's assumptions, values, and beliefs about the school's purpose, instructional methods, and rapport" (p. 309).

The ability to adapt to a given situation is a principal's most important emotional competency, followed by emotional self-awareness. Mayer and Salovey (1997) have stressed the importance of "... recognizing how an individual and those around the individual are feeling... and the capacity to perceive and to express feelings" (p. 19). Influence, positive outlook, and organizational awareness have further showed a small effect on the principals' position, which was in accordance with Cheng's (1994) findings. Hooijberg, Dodge and Hunt (1997) additionally advised that "the cognitive complexity, social intelligence, and behavioral complexity of strategic leaders positively affects the essence of strategic leadership" (p. 539). According to Bastian et al. (2005), this information is important since "emotional intelligence might enable a person to become aware of relationships between mood and performance and to direct their efforts into activities best suited for certain emotional states."

The coefficient of determination indicated that a superintendent will benefit most from the ability to manage conflict, and maintain a positive outlook. A superintendent's greatest effects are derived from inspirational leadership and influence. By utilizing these abilities, studies have indicated that persons with high EI scores make better managers and are better able to build superior team efficiency (Brackett \& Salovey, 2006; Gardner \& Stough, 2002; Goleman, 1998; Hollenbeck, De Rue, \& Guzzo, 2004; Jain \& Sinha, 2005; Rosete \& Ciarrochi, 2005; Van Rooy \& Viswesvaran, 2004). Moreover, maintaining a positive outlook is important, since as Leithwood et al. (2008) advised:

The most successful school leaders are open-minded and ready to learn from others. They are also flexible rather than dogmatic in their thinking within a system of core values, persistent (e.g., in pursuit of high expectations of staff motivation, commitment, learning and achievement for all), resilient and optimistic. Such traits help explain why successful leaders facing daunting conditions are often able to push forward when there is little reason to expect progress (p. 14).

The greatest effects for the mean of the three leadership stratas were coach and mentor, positive outlook, and empathy. However, Feyerherm and Rice (2002) posited, “...one must look at the various components. Not all 
components are related to the same performance outcomes" (p. 359). Correspondingly, Rode, Arthaud-Day, Baldwin, Bommer, Mooney, Near and Rubin (2007) found emotional intelligence to be "...significantly related to performance only in contexts with explicitly strong emotive content. In other words, the type of performance does matter" (p. 412). This study found that not all competencies had an effect on longevity in a leadership position; however, as Feyerherm and Rice (2002) admonished, "there is more complexity associated with the relationship of team performance and team and leader emotional intelligence than meets the eye" (p. 359)

\section{Conclusions}

The role of an educational leader can be, at once, exciting, fulfilling, challenging, and demanding. Managing one's emotions, in the effort to overcome obstacles and remain successful in the long-term in an educational leadership position requires diligence and care. There are several factors influencing the relationship between longevity in an educational leadership position and a leader's emotional intelligence and resilience in the face of adversity. While findings from this study have failed to yield results linking all emotional competencies to the former body of research, several competencies do appear to have an effect on the longevity in an educational leadership position. Assistant principals especially benefit from the competencies of coaching and mentoring, conflict management, empathy, organizational awareness, inspirational leadership, and influence. Principals benefit most from the ability to adapt, to influence their staff and resolve conflicts, and to have a positive outlook. Superintendents benefit most from the ability to manage conflict, coach and mentor, inspirational leadership and influence, and the ability to maintain a positive outlook and be achievement oriented. The limitations of this study include the small participant size.

\section{References}

Ackerman, R. H., \& Maslin-Ostrowski, P. (2004). The Wounded Educational Leader, 61(7), 1-6. Retrieved from http://www.ascd.org/publications/educatonal-leadership/apr04/vol61/num07/The-Wounded-Leader.aspx

Armstrong, A., Critchley, C. R., \& Galligan, R. F. (2011). Emotional intelligence and psychological resilience to negative life events. Personality and Individual Differences, 51, 331-336. https://doi.org/10.1016/j.paid.2011.03.025

Austin, E. J., Brackett, M. A., Mayer, J. D., Minski, P. S., \& Saklofkse, D. H. (2003). Factor structure and validity of a trait emotional intelligence measure. Personality and Individual Difference, 34(4), 707-721. https://doi.org/10.1016/S0191-8869(02)00056-9

Austin, E. J., Egan, V., \& Saklofske, D. H. (2005). Personality, well-being and health correlates of trait emotional intelligence. Personality and Individual Differences, 38(3), 547-558. https://doi.org/10.1016/j.paid.2004.05.009

Bar-On, R. (2006). The Bar-On model of emotional-social intelligence (ESI). Psicothema, 18, 13-25.

Bastian, V. A., Burns, N. R., \& Nettelbeck, T. (2005). Emotional intelligence predicts life skills, but not as well as personality and cognitive abilities. Personality and Individual Differences, 39(6), 1135-1145. https://doi.org/10.1016/j.paid.2005.04.006

Boyatzis, R. E. (2009). Competencies as a behavioral approach to emotional intelligence. Journal of Management Development, 28(9), 749-770. https://doi.org/10.1108/02621710910987647

Brackett, M. A., Mayer, J. D., \& Warner, R. M., (2004). Emotional intelligence and its relation to everyday behavior. Personality and Individual Differences, 36, 1387-1402. https://doi.org/10.1016/S0191-8869(03)00236-8

Brackett, M. A., \& Salovey, P. (2006). Measuring emotional intelligence with the Mayer-Salovey-Caruso emotional intelligence test (MSCT). Psicotherma, 18, 34-41.

Burns-Neilson, D. (2002). Who will teach Montana's children; 2002 follow up study. Montana Board of Public Education.

Cheng, Y. C. (1994). Principal's leadership as a critical factor for school performance: Evidence from multi-levels of primary schools. School Effectiveness and School Improvement, 5(3), 299-317. https://doi.org/10.1080/0924345940050306

Chronbach, L. J. (1970). We should measure change—or should we. Psychological Bulletin, 74(1), 68-80. https://doi.org/10.1037/h0029382

Cohen, J. (1994). The earth is round $(\mathrm{p}<$.05). American Psychologist, 49, 997-1003. https://doi.org/10.1037/0003-066X.49.12.997 
Doyle, D., \& Locke, G. (2014). Lacking leaders: The challenges of principal recruitment selection, and placement. Washington, D.C.: Thomas B. Fordham Institute.

Feyerherm, A. E., \& Rice, C. L. (2002). Emotional intelligence and team performance: The good, the bad and the ugly. The International Journal of Organizational Analysis, 10(4), 343-362. https://doi.org/10.1108/eb028957

Gannon, N., \& Ranzijn, R. (2004). Does emotional intelligence predict unique variance in life satisfaction beyond IQ and personality? Personality and Individual Difference, 38, 1353-1364. https://doi.org/10.1016/j.paid.2004.09.001

Gardner, L., \& Stough, C. (2002). Examining the relationship between leadership and emotional intelligence in senior level managers. Leadership and Organizational Development Journal, 23(2), 68-78. https://doi.org/10.1108/01437730210419198

Goleman, D. (1998). Working with emotional intelligence. New York, NY: Bantam. https://doi.org/10.1002/lt1.40619981008

Hauke, J., \& Kossowski, T. (2011). Comparison of values of pearson's and spearman's correlation coefficients on the same sets of data. Quaestiones Geographicae, 30(2), 87-93. https://doi.org/10.2478/v10117-011-0021-1

Holcomb, Z. C. (2017). SPSS basics; Techniques for a first course in statistics (6th ed.). Fred Pyrczak, Publisher, A California Corporation, Glendale, CA.

Hollenbeck, J. R., De Rue, D. S., \& Guzzo, R. (2004). Bridging the gap between I/O research and HR practice: Improving team composition, team training, and team task design. Human Resource Management, 43(4), 353-366. https://doi.org/10.1002/hrm.20029

Hooijberg, R., Dodge, G. E., \& Hunt, J. G. (1997). Leadership complexity and development of the leaderplex model. Journal of Management, 23(3), 375-408. https://doi.org/10.1177/014920639702300305

Jain, A. K., \& Sinha, A. K. (2005). General health in organizations: Relative relevance of emotional intelligence, trust, and organizational support. International Journal of Stress Management, 3(12), 257-273. https://doi.org/10.1037/1072-5245.12.3.257

Klitz, G., Danzig, A., \& Szecsy, E. (2004). Learner centered leadership: A mentoring model for the professional development of school administrators. Mentoring \& Tutoring: Partnership in Learning, 12(2), 135-153. https://doi.org/10.1080/1361126042000239901

Leithwood, K., Harris, A., \& Hopkins, D. (2008). Seven strong claims about successful school leadership. School Leadership \& Management, 28(1), 27-42. https://doi.org/10.1080/13632430701800060

Manna, P. (2015). Developing excellent school principals to advance teaching and learning: Considerations for state policy. The Wallace Foundation, Washington, D.C.

Martin, A. (2007). The changing nature of leadership. Center for Creative Leadership. Retrieved from $\mathrm{http} / / /$ www.ccl.org/leadership/pdf/research/natureleadership.pdf

Maulding, W. S. (2002). Emotional Intelligence and Successful Leadership. Presented at the Annual Meeting of the Southern Regional Council on Educational Administration. Kansas City, KS.

Maulding, W. S., Leonard, E., Peters, G. B., Roberts, J., \& Sparkman, L. (2012). Emotional intelligence and resilience as predictors of leadership in school administrators. Journal of Leadership Studies, 5(4), 20-29. https://doi.org/10.1002/j1s.20240

Mayer, J. D., Caruso, D., \& Salovey, P. (1999). Emotional intelligence meets traditional standards for an intelligence. Intelligence, 27, 267-298. https://doi.org/10.1016/S0160-2896(99)00016-1

Mayer, J. D., \& Salovey, P. (1997). What is emotional intelligence? Emotional Development and Emotional Intelligence; Educational Implications. New York. NY: Basic Books.

Mendels, P. (2016). Building principal pipelines: A job that urban districts can do. The Wallace Foundation. New York, NY.

Norušis, M. J. (2005). SPSS 13.0 Guide to data analysis. Upper Saddle River, NJ: Prentice Hall.

Pallant, J. (2010). SPSS survival manual. Berkshire, England: Open University Press. McGraw-Hill Education.

Patterson, J., \& Patterson, J. (2004). Leading in tough times: Sharing the lead. Educational Leadership, 61(7), 
$74-78$.

Petrides, K. V., \& Furnham, A. F. (2002). Trait emotional intelligence: behavioral validation in two studies of emotion recognition and reactivity to mood induction. European Journal of Personality, 17(1), 39-57. https://doi.org/10.1002/per.466

Rode, J. C., Arthaud-Day, M. L., Baldwin, T. T., Bommer, W. H., Mooney, C. H., Near, J. P., \& Rubin, R. S. (2007). Emotional intelligence and individual performance: Evidence of direct and moderated effects. Journal of Organizational Behavior, 28, 399-404. https://doi.org/10.1002/job.429

Rosete, D., \& Ciarrochi, J. (2005). Emotional intelligence and its relationship to workplace performance out comes of leadership effectiveness. Leadership Organizational Development, 26, 388-399. https://doi.org/10.1108/01437730510607871

Salkind, N. J. (2010). Encyclopedia of research design. Sage Research Methods. https://doi.org/10.4135/9781412961288

Salovey, P., Bedell, B. T., Detwieler, J. B., \& Mayer, J. D. (1999). Coping intelligently: Emotional intelligence and the coping process. New York, NY: Oxford Press.

Schutte, N. S., Bhullar, N., Malouff, J. M., Rooke, S. E., \& Thorsteinsson, E. B. (2007). An investigation of the relationship between emotional intelligence and health. Personality and Individual Differences, 42(6), 921-933. https://doi.org/10.1016/j.paid.2006.09.003

Schutte, N. S., Hollander, S., Malouff, J. M., \& Simunek, J. M. (2002). Characteristic emotional intelligence and emotional well-being. Psychology Press, 16(6), 769-785. https://doi.org/10.1080/02699930143000482

Schutte, N. S., \& Malouff, J. M. (2011). Emotional intelligence mediates the relationship between mindfulness and subjective well-being. Personality and Individual Differences, 50, 1116-1119. https://doi.org/10.1016/j.paid.2011.01.037

Steinberg, W. J. (2011). Statistics alive. Sage Publications, Inc. Thousand Oaks, CA.

Stoltz, P. (2001). Your adversity quotient. Innovative Leader, 10(2), 1-55.

Tavakol, M., \& Dennick, R. (2011). Making sense of Cronbach's alpha. International Journal of Medical Education, 2, 53-55. https://doi.org/10.5116/ijme.4dfb.8dfd

Van Rooy, D. L., \& Viswesvaran, C. (2004). Emotional intelligence: a meta-analytic investigation of predictive validity and nomological net. Journal of Vocational Behavior, 65(1), 71-95. https://doi.org/10.1016/S0001-8791(03)00076-9

Wing, J. F., Byrne, B., \& Schutte, N. S. (2006). The effect of positive writing on emotional intelligence and life satisfaction. Journal of Clinical Psychology, 62(10), 1291-1302. https://doi.org/10.1002/jclp.20292

Wong, C., \& Law, K. S. (2002). The effects of leader and follower emotional intelligence. The Leadership Quarterly, 13, 243-274. https://doi.org/10.1016/S1048-9843(02)00099-1

\section{Copyrights}

Copyright for this article is retained by the author, with first publication rights granted to the journal.

This is an open-access article distributed under the terms and conditions of the Creative Commons Attribution license (http://creativecommons.org/licenses/by/4.0/). 